\title{
Efficacy of Fertilizers and Biorationals against the Fungal Pathogen Stemphylium vesicarium Causing Foliar Blight of Onion
}

\author{
Bhavya Mishra* and R.P. Singh \\ Department of Plant Pathology, College of Agriculture, G. B. Pant University of Agriculture and \\ Technology, Pantnagar-263145, Uttarakhand, India \\ *Corresponding author
}

\section{A B S T R A C T}

\begin{tabular}{|l|}
\hline Ke y w o r d s \\
Stemphyliumvesicar \\
ium, Biorationals, \\
Fertilizers, \\
Inhibition, in vitro, \\
Urea. \\
\hline Article Info \\
\hline $\begin{array}{l}\text { Accepted: } \\
\text { 26 August } 2017 \\
\text { Available Online: } \\
\text { 10 September } 2017\end{array}$ \\
\hline
\end{tabular}

Onion is one of the most important commercial crops grown all over the world. The crop is attacked by many diseases which cause yield losses and result in lowering the quality and export potential of the produce. Stemphylium blight caused by Stemphylium vesicarium (Wallr.) Simmons is one such disease, which has become a serious problem since past few years, especially in Northern and Eastern India. Foliar application of fertilizers and biorationals is gaining popularity. So, their effect on the pathogen Stemphylium vesicarium was assessed. In vitro study was conducted for testing these chemicals at different doses. The results of the study revealed thaturea was most effective in inhibiting the fungal growth at all the tested concentration. It was also found that soluble NPK and Potassium nitrate promoted the fungal growth at all the concentration. Among biorationals, bromonitropropanol gave the highest mycelial inhibition (73.72\%), while sodium and potassium bicarbonates at lower concentration promoted the fungal growth, but inhibited the growth at higher concentration. These results provide the insight about the possible effects that foliar spray of fertilizers and biorationals can have on the fungal pathogen and their potential use in the disease management strategy under field conditions.

\section{Introduction}

Onion (Allium cepa L.) is one of the most important commercial crops grown all over the world. India is the second largest producer of onion in the world, but still it is far behind many countries in terms of productivity. Amongvarious other reasons, diseases are one of the major constraints in onion production. The crop is besieged by many diseases which cause yield losses as well as result in lowering the quality and export potential of the produce. Stemphylium blight caused by Stemphylium vesicarium (Wallr.) Simmons is one such disease, which was not a major economic threat till now, but since past few years, has become a serious problem throughout the country, especially in Northern and Eastern India. Methods suggested for the management of Stemphylium blight are cultural practices, field sanitation, host resistance, biocontrol and chemical control. Farmers tend to use chemicals more as it is a quick acting remedy. Quick and ensured effectiveness of chemical pesticide on pathogen gives it an edge over other methods of management. But use of chemicals has the drawbacks like development of resistance in the pathogen against a particular chemical or group of chemicals due to the repetitive use 
of same chemical. Also, problems of pesticide residue accumulation in the edible plant parts deteriorates the quality of harvested produce and makes the produce less desirable or unfit for consumption and export purposes. Therefore, it is need of the hour to find out effective and safe chemicals that can be included in integrated pests management programme.

Application of nutrients strengthen the plants such that they can withstand the disease to an acceptable level, or at least to a level at which further control by other management practices becomes more successful and less expensive. In past years, use of soluble fertilizers and some biorational compounds by foliar application has become popular amongst the farmers. Its influence on the growth and development of the foliar pathogens has been studied only in limited cases. Nutrients can decrease the severity of a disease but can also increase the severity of the disease incidence of other diseases or have a completely opposite effect in a different environment (Marschner, 1995; Graham and Webb, 1991). Veresoglou et al., (2013) concluded that some plant species such as Solanum spp. have the potential to show reduced disease severity following $\mathrm{N}$ fertilization. Wang et al., (2013) in his review evaluated the potential for improving plant stress resistance by modifying $\mathrm{K}$ fertilizer inputs.

But no study in this regard has been done on Stemphylium vesicarium or any other foliar pathogen of onion crop. So, the present study was conducted to assess the effects of some popularly used fertilizers and biorationals on the growth of the fungal pathogen.

\section{Materials and Methods}

The effect of chemicals other than pesticides on the growth of the test pathogen $S$. vesicarium was studied using four popular fertilizers and three biorational compounds as mentioned in Table 1, under in vitro conditions by Poison Food Technique (Grover and Moore, 1962) on PDA medium. All the chemicals were tested at three different doses viz. a field recommended dose for foliar spray, a dose lower than recommended dose and a dose higher than it.

In this technique, double strength Potato Dextrose Agar (PDA) medium was prepared:

Peeled potato: $400 \mathrm{~g}$

Dextrose: $40 \mathrm{~g}$

Agar agar: $40 \mathrm{~g}$

Distilled water: $1000 \mathrm{ml}$

Required amount of peeled potato were cut in to fine pieces. Then, boiled in 500ml distilled water for 30 minutes and filtered through muslin cloth to get the extract. $40 \mathrm{~g}$ of dextrose and $40 \mathrm{~g}$ of agar agar were dissolved in $500 \mathrm{ml}$ boiling water separately. Thereafter, potato extract was added in boiling mixture and stirred thoroughly with glass rod and finally volume was adjusted to 1.0 litre. The $\mathrm{pH}$ was adjusted to 7.0 and media was equally distributed in $250 \mathrm{~mL}$ conical flasks and sterilized by autoclaving at 15 psi $\left(121.6^{0} \mathrm{C}\right)$ for 20 minutes.

Stock solution of the chemicals, each of $10 \%$, was prepared by dissolving required quantity of chemicals in a measured volume of sterilized distilled water and added to double strength PDA medium just before pouring so as to obtain the desired concentration. The amount of stock solution to be added to medium was calculated using following formula:

\section{$\mathrm{C} 1 \mathrm{~V} 1=\mathrm{C} 2 \mathrm{~V} 2$}

Where,

$\mathrm{C} 1=$ Concentration of stock solution (\%) 
$\mathrm{C} 2=$ Desired concentration $(\%)$

$\mathrm{V} 1=$ Volume $(\mathrm{ml})$ of stock solution to be added

$\mathrm{V} 2=$ Measured volume $(\mathrm{ml})$ of the PDA medium

Medium amended with desired concentration of fertilizer or biorational compound was poured separately into sterilized Petri plates. About $20 \mathrm{~mL}$ of melted poisoned PDA was poured in each sterilized Petri plate and allowed to solidify. After solidification of medium, the plates were inoculated in the centre with $5 \mathrm{~mm}$ mycelial culture discs, obtained with the help of sterilized cork borer, from 10 days old culture of Stemphylium vesicarium. Unamended PDA plates inoculated with the test pathogen served as control. For each concentration of each treatment, three replications were maintained. Inoculated plates were incubated at $24 \pm 1^{\circ} \mathrm{C}$ temperature in B.O.D. incubator.

Data on radial growth of the fungus were recorded by measuring the colony diameter after 10 days of inoculation and percent mycelial growth inhibition was calculated as described by Vincent (1927).

$\mathrm{I}=\frac{\mathrm{C}-\mathrm{T}}{\mathrm{C}} \times 100$

Where,

$\mathrm{I}=$ Inhibition percent

$\mathrm{C}=$ Growth of the test fungus in control (mm)

$\mathrm{T}=$ Growth of the test fungus in treatment (mm)

Analysis of the replicated data on the mycelial growth of the test fungus was done by F-test using the STPR Software.

\section{Results and Discussion}

The results of the study as presented in Table 2revealed that among the fertilizers, urea was found to be best in inhibiting the fungal growth at all the tested concentration. Urea at 1 per cent gave the highest per cent inhibition (73.72\%) followed by 0.7 per cent and 0.4 per cent concentrations (67.15 and57.66\% inhibition, respectively).It was also found that soluble NPK and Potassium nitrate promoted the fungal growth at all the concentration and their growth promoting effect increased along with their concentration. Soluble potash $(0.8$ $\%)$ gave mycelial inhibition of 53.28 per cent but as its concentration increased to 1.2 per cent the mycelial inhibition was reduced to 38.32 per cent (Fig 1 and 2).

Veverka et al., (2007) studied the sensitivity of oomycota, saprophytic and pathogenic fungi to urea, ammonium nitrate and UAN (urea plus ammonium nitrate) in laboratory trials and reported that the most toxic was urea especially against Alternaria tenuissima, Botrytis cinerea and Cladosporium cladosporioides. These results support our findings that urea was found to be most effective in inhibiting the fungal mycelial growth.

In vitro studies was carried out by Mohamed et al., (2014) on effect of sodium nitrate level as a fertilizer on aggressiveness of the fungus Rhizoctonia solani growing on Czapek's Dox agar medium supplemented with different levels of fertilizer. The obtained results revealed that higher level of nitrate in growth medium clearly enhanced the aggressiveness of the fungus. These results are in agreement with our study that potassium nitrate promoted the fungal growth at all tested concentration. El-Bramawy and Shaban (2010) studied the effects of potassium fertilization on resistance to rust and chocolate spot diseases of faba bean and 
reported that foliar application of potassium provided resistance in desired direction. This study supports our findings that soluble potash reduces the fungal growth to a great extent.

Table.1 Fertilizers and biorationals used for in vitro studies

\begin{tabular}{llccc}
\hline S.No & \multicolumn{1}{c}{ Common Name } & $\begin{array}{c}\text { Doses Tested }(\%) \\
\text { Lecommended } \\
(\mathbf{L})\end{array}$ & $\begin{array}{c}\text { Higher } \\
(\mathbf{R})\end{array}$ \\
\hline (H)
\end{tabular}

Table.2 Effect of fertilizers on the radial growth of Stemphylium vesicarium

\begin{tabular}{|c|c|c|c|}
\hline Treatments & & Mycelial Growth* (mm) & Radial growth inhibition (\%) \\
\hline \multirow{3}{*}{ Soluble NPK } & $\mathrm{L}$ & 48.50 & -6.20 \\
\hline & $\mathrm{R}$ & 59.33 & -29.93 \\
\hline & $\mathrm{H}$ & 61.67 & -35.04 \\
\hline \multirow[t]{3}{*}{ Potassium nitrate } & $\mathrm{L}$ & 47.00 & -2.92 \\
\hline & $\mathrm{R}$ & 51.33 & -12.41 \\
\hline & $\mathrm{H}$ & 59.33 & -29.93 \\
\hline \multirow[t]{3}{*}{ Soluble potash } & $\mathrm{L}$ & 21.33 & 53.28 \\
\hline & $\mathrm{R}$ & 26.83 & 41.24 \\
\hline & $\mathrm{H}$ & 28.17 & 38.32 \\
\hline \multirow[t]{3}{*}{ Urea } & $\mathrm{L}$ & 19.33 & 57.66 \\
\hline & $\mathrm{R}$ & 15.00 & 67.15 \\
\hline & $\mathrm{H}$ & 12.00 & 73.72 \\
\hline Check & & 45.67 & - \\
\hline \multirow[t]{3}{*}{ S.Em \pm} & $\mathrm{a}$ & 0.87 & \\
\hline & $\mathrm{b}$ & 0.68 & \\
\hline & $\mathrm{a} \times \mathrm{b}$ & 1.52 & \\
\hline \multirow[t]{3}{*}{$\mathrm{CD}$ at $5 \%$} & $\mathrm{a}$ & 2.53 & \\
\hline & $\mathrm{b}$ & 1.96 & \\
\hline & $\mathrm{a} \times \mathrm{b}$ & 4.38 & \\
\hline
\end{tabular}

*all values are mean of three replications

$\mathrm{L}$ is dose lower than recommended, $\mathrm{R}$ is recommended dose and $\mathrm{H}$ is dose higher than recommended.

$\mathrm{S} . \mathrm{Em} \pm$ is standard error of mean.

"a" stands for first level of treatment i.e. fertilizers, "b" stands for second level of treatment i.e. doses of the chemical and " $a \times$ b" stands for the interaction of the two levels of treatment. 
Table.3 Effect of biorationals on the radial growth of Stemphylium vesicarium

\begin{tabular}{lccc}
\hline Treatments & & Mycelial Growth*(mm) & Radial growth inhibition (\%) \\
\hline Potassium bicarbonate & $\mathrm{L}$ & 51.33 & -12.41 \\
& $\mathrm{R}$ & 30.00 & 34.31 \\
Sodium bicarbonate & $\mathrm{H}$ & 22.33 & 51.09 \\
& $\mathrm{~L}$ & 50.83 & -11.31 \\
& $\mathrm{R}$ & 30.00 & 34.31 \\
Bromonitropropanol & $\mathrm{H}$ & 26.00 & 43.07 \\
& $\mathrm{~L}$ & 12.00 & 73.72 \\
& $\mathrm{R}$ & 15.00 & 67.15 \\
Check & $\mathrm{H}$ & 17.33 & 62.04 \\
\hline S.Em \pm & & 45.67 & - \\
& $\mathrm{a}$ & 1.04 & \\
CD at 5\% & $\mathrm{b}$ & 0.89 & \\
& $\mathrm{a}$ b & 1.79 & \\
& $\mathrm{a}$ & 3.03 & \\
\hline
\end{tabular}

*all values are mean of three replications

$\mathrm{L}$ is dose lower than recommended, $\mathrm{R}$ is recommended dose and $\mathrm{H}$ is dose higher than recommended.

$\mathrm{S} . \mathrm{Em} \pm$ is standard error of mean.

"a" stands for first level of treatment i.e. biorationals, "b" stands for second level of treatment i.e. doses of the chemical and "a x b" stands for the interaction of the two levels of treatment.

Fig.1 Comparative graph of radial growth inhibition of S. vesicarium

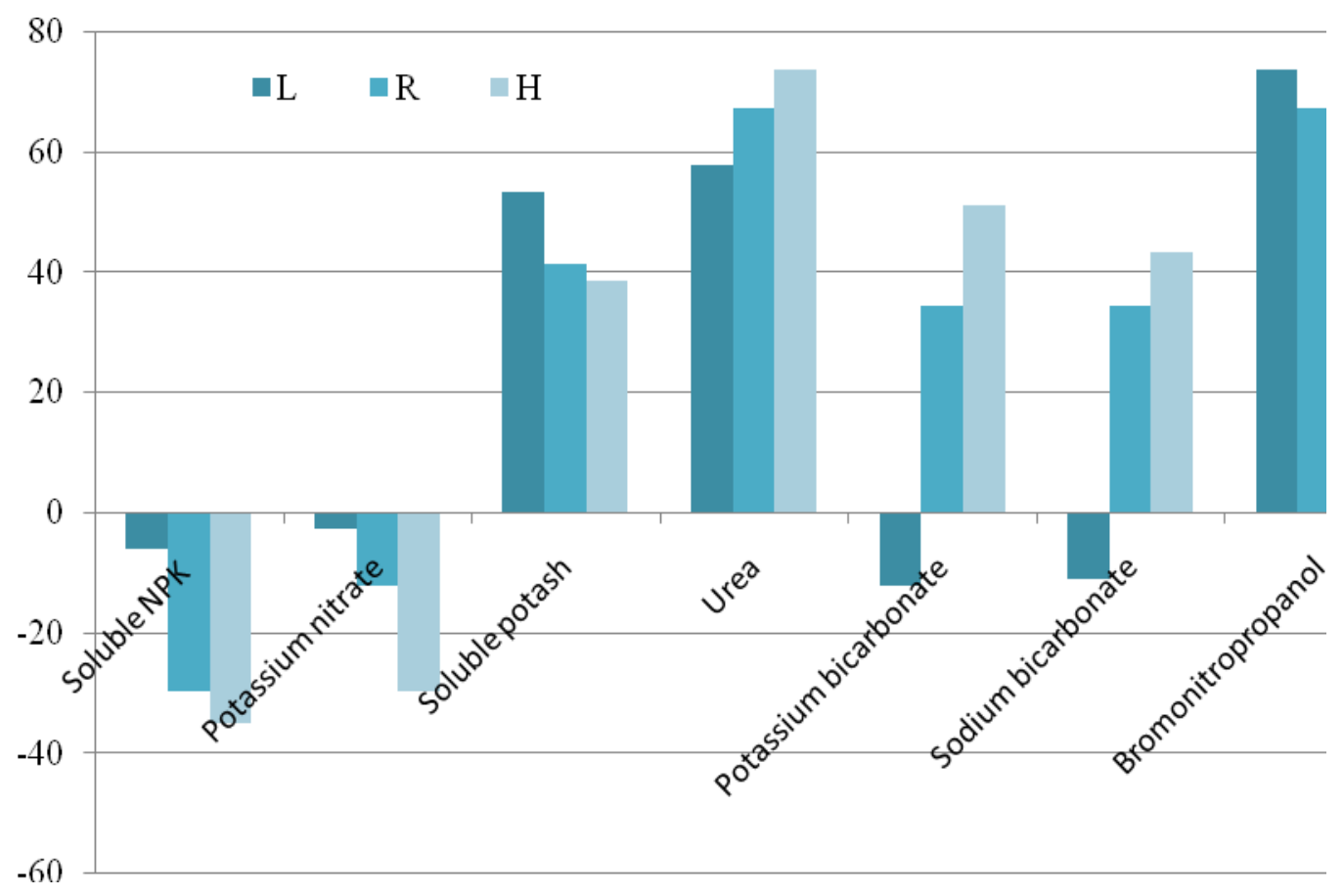


Fig.2 Effect of fertilizers and biorationals on the radial growth of Stemphylium vesicarium

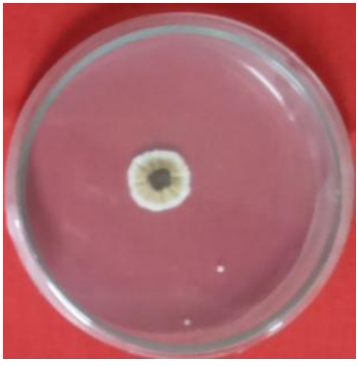

Soluble potash

$(0.8 \%)$

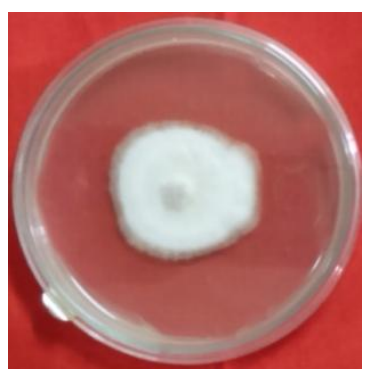

Potassium nitrate

$(0.5 \%)$

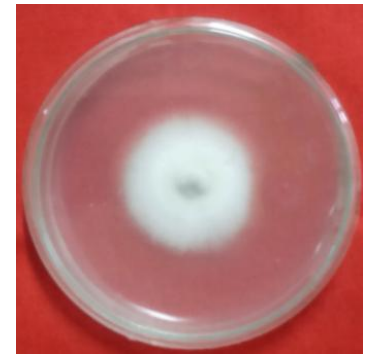

Sodium bicarbonate $(0.5 \%)$

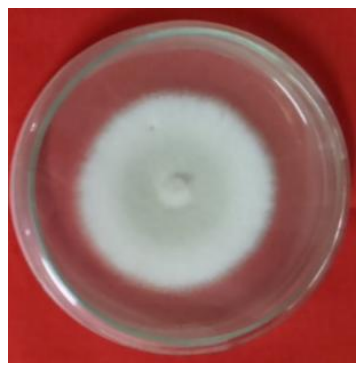

Soluble NPK (1.5\%)

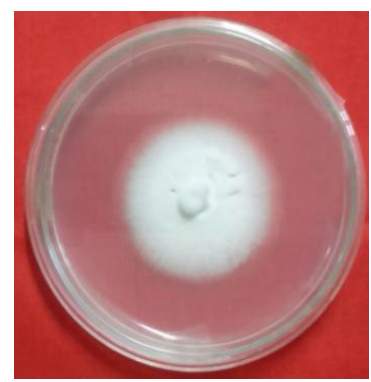

Potassium

bicarbonate $(0.5 \%)$

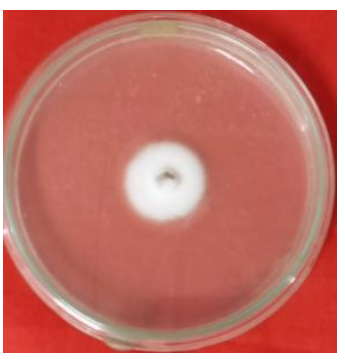

Sodium bicarbonate $(1.5 \%)$

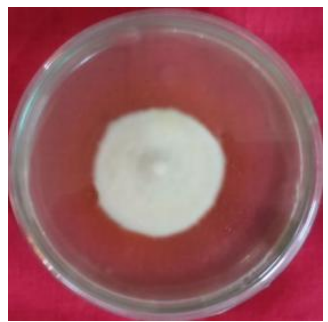

Check

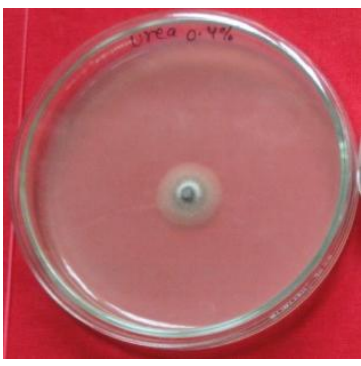

Urea $(0.4 \%)$

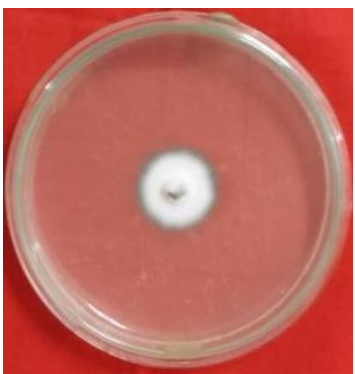

Potassium

bicarbonate $(1.5 \%)$

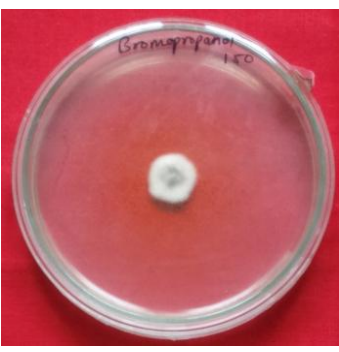

Bromonitropropano

$(0.015 \%)$ 
Among biorational chemicals, Bromonitropropanol was found to be most effective in inhibiting the mycelial growth of Stemphylium vesicarium (Table 3). At lower concentration $(0.015 \%)$ it gave highest per cent inhibition of mycelial growth $(73.72 \%)$. On increasing the concentration, the per cent inhibition decreased. This may be due to the fact that bromonitropropanol is not a fungicide, it is a host defence inducing compound and that is why its efficacy may have decreased on increasing the concentration.Sodium bicarbonate and Potassium bicarbonate at low concentration of 0.5 per cent have growth promoting effect but at recommended (1\%) and higher $(1.5 \%)$ concentrations, inhibition of mycelial growth was observed. It was 34.31 and 51.09 per cent in potassium bicarbonate and 34.31 and 43.07 per cent in sodium bicarbonate (Fig 1 and 2).From this we can draw inference that if these two chemicals are used as foliar spray at lower concentration, they may enhance the disease. So, they must be used only at recommended doses or higher.

Li (2012) have suggested the use of products containing potassium bicarbonate for the management of powdery mildew in organic cucurbit cultivation. Use of potassium bicarbonate and sodium bicarbonate (baking soda) at the rate of 2.5-3 pounds per acre has been recommended to control the spread of onion powdery mildew (Leveillulataurica) by the Utah State University Extension Service (2008). This supports the fact that these biorationals (sodium bicarbonate and potassium bicarbonate) may help in reducing the disease when used at recommended doses or higher. But when used at lower doses, might increase the disease severity. So far, there have been only reports of field recommendations of these biorationals, but there in vitro efficacy against any pathogen has not been tested and this study is probably the first report of direct antifungal activity.
Thus it can be suggested that fertilizers and chemicals like urea, soluble potash, bromonitropropanol etc. can be included in integrated pest management programmes as they will not only provide nutrition and strengthen the plants but also exhibit fungicidal properties. However, their doses is an issue which needs further studies because some chemicals like potassium bicarbonate and sodium bicarbonate were found to inhibit fungal growth at higher concentration but at lower concentrations, they may promote fungal growth and enhance the disease. Fertilizers like soluble NPK and potassium nitrate are shown to have a growth promoting effect on $S$. vesicarium. Thus, they should be judiciously used. But the effects of these fertilizers and biorationals may vary from crop to crop and pathogen to pathogen, and so their interaction with the various plant-patho systems should be further studied.

\section{References}

El-Bramawy, M.A.S.A., and Shaban, W.I. 2010. Effects of potassium fertilization on agronomic characters and resistance to chocolate spot and rust diseases in faba bean. Tunisian Journal of Plant Protection. 5: 131-150.

Graham, D. R., and Webb, M. J. 1991. Micronutrients and disease resistance and tolerance in plants. In: Micronutrients in Agriculture. (Eds.) J.J. Mortvedt, F.R. Cox, L.M. Shuman, R.M. Welch. Soil Science Society of America, Madison, Wisconsin, USA. Pp 329-370.

Grover, R. K., and Moore, J. D. 1962.Toxicometric studies of fungicides against brown rot organisms Sclerotiniafructicola and S. laxa. Phytopathology. 52: 876-880.

Li, Y.H., 2012.Powdery mildew of cucurbits.Connecticut Agricultural Experiment 
Station.http://www.ct.gov/caes/lib/caes/ documents/publications/fact_sheets/plan t_pathology_and_ecology/powdery_mil dew_of_cucurbits_10-31-12.pdf Accessed on 03-08-2017.

Marschner, H., 1995. Mineral Nutrition of Higher Plants.2nd ed. Academic Press, London. 889p.

Mohamed, M.H., Gado, E.A.M., El-Deeb, S.H. \& Mostafa, M.H. 2014.Effect of nitrate levels as a fertilizer or as a fungal nutrition on the aggressiveness of Rhizoctonia solani on faba bean. European Journal of Advanced Research in Biological and Life Sciences. 2:1-13.

Utah State University Extension. 2008. Utah Pests Fact Sheet. April 2008.
Veresoglou, S.D., Barto, E.K., Menexes, G. Rillig, M.C. 2013. Fertilization affects severity of disease caused by fungal plant pathogens. Plant Pathology. 62:961-969.

Veverka, K.; Štolcová, J. and Růžek, P. 2007. Sensitivity of Fungi to Urea, Ammonium Nitrate and their Equimolar Solution UAN. Plant Protection Sciences. 43(4): 157-164.

Vincent, J. M., 1927. Distortion of fungal hyphae in the presence of certain inhibitors.Nature.159: 850.

Wang, M., Zheng, Q., Shen, Q. and Guo, S. 2013. The critical role of potassium in plant stress response. International Journal of Molecular Sciences. 14:7370-7390.

\section{How to cite this article:}

Bhavya Mishra and Singh, R.P. 2017. Efficacy of Fertilizers and Biorationals against the Fungal Pathogen Stemphylium vesicarium Causing Foliar Blight of Onion. Int.J.Curr.Microbiol.App.Sci. 6(9): 2925-2932. doi: https://doi.org/10.20546/ijcmas.2017.609.359 